\title{
Fetichismos da carne: consumismo midiático no capitalismo contemporâneo
}

\begin{abstract}
Rodrigo Diaz de Vivar y Soler ${ }^{1}$
1 Doutorando em Filosofia pela UNISINOS, Mestre em Psicologia pela UFSC, Bacharel em Psicologia pela UNESC. Professor no Ensino Superior no Centro Universitário Estácio de Santa Catarina, Brasil. E-mail: diazsoler@gmail.com
\end{abstract}

So ya, thought ya, Might like to go to the show to feel the warm thrill of confusion.

That space cadet glow, i've got some bad news for you sunshine. (Pink Floyd - In The Flesh?)

RESUMO: Este artigo procura apresentar os resultados de uma pesquisa realizada junto a estudantes de uma instituição superior de ensino localizada no interior do estado de Santa Catarina em que buscou-se observar através de entrevistas abertas e semiestruturadas como esse estudantes são afetadas pelo consumismo midiático, sobretudo a partir da noção de fetichismo inscrita dentro do pensamento do intelectual alemão Walter Benjamin. A partir da elaboração de sete categorias que envolviam a opinião dos entrevistados sobre as propagandas assistidas por eles, os seus produtos de consumo, a sua relação com a Internet, a representação da juventude nas grandes produções midiáticas, o seu conhecimento acerca do consumo sustentável e a opinião acerca das propagandas de cervejas e de bancos percebe-se que o fetichismo é importante produtor de modos de subjetivação orquestrados em modos de governamentalidades responsáveis por fazer do consumo a única forma de existência possível na nossa sociedade.

Palavras-chave: Fetichismo, Capitalismo, Contemporaneidade.

Fetishism's of the flesh: media's consumism in the contemporary capitalism ABSTRACT: This article presents the results of a survey of students of a higher educational institution located in the state of Santa Catarina in which we sought to observe through open and semi structured interviews such students are affected by media consumption, especially from the notion of fetishism entered into the thinking of German intellectual Walter Benjamin. From the preparation of seven categories involving the opinion of respondents on advertisements assisted them, their consumer products, their relationship with the Internet, youth representation in major media productions, their knowledge about sustainable consumption and opinion about the advertising of beer and banks realize that fetishism is important producer of subjectivity modes orchestrated in governamentalidades modes responsible for making the only form of existence possible consumption in our society.

Keywords: Fetishism, Capitalism, Contemporary. 


\section{INTRODUÇÃO}

Essa pesquisa é resultado de um estudo desenvolvido junto a estudantes do Ensino Superior em uma instituição localizada no interior do estado de santa Catarina. Através da elaboração de um roteiro composto por entrevistas abertas e semiestruturadas, buscou-se compreender quais os sentidos e os significados do consumismo midiático no contexto do capitalismo contemporâneo através das suas formas de fetichização da subjetividade.

No que se refere ao desenvolvimento metodológico nosso trabalho é composto pelas seguintes categorias de análise: $C 1-$ Da opinião sobre a propaganda dirigida aos jovens; C2 - Do conhecimento acerca da obsolescência programada; C3 - Dos cinco produtos mais utilizados pelos entrevistados; C4 - Do conseguir ou não viver sem Internet; C5 - De como a juventude é retratada nas propagandas; C6 - Do conhecimento acerca do consumo sustentável e, finalmente, C7 - Da opinião acerca das propagandas de cervejas e bancos.

A perspectiva teórica que embasa o trabalho refere-se às contribuições de Walter Benjamin acerca do capitalismo compreendido não somente como fenômeno econômico, mas também como fetichismo produtor de modos de subjetivação orquestrados em modos de governamentalidades responsáveis por fazer do consumo a única forma de existência possível na nossa sociedade.

Por fim, destaca-se que nosso texto está estruturado em dois momentos. No primeiro deles apresentamos as análises das falas dos sujeitos entrevistados através de um recorte transversal sobre cada uma de suas categorias. Em seguida nos propusemos em debruçarmo-nos sobre o papel do consumismo midiático na nossa sociedade tendo como pano de fundo a produção do que, provocativamente chamamos de fetichismos da carne. Nossas considerações finais são dedicadas a explorar a relação agonística entre as formas de fetichismos contemporâneos e os processos de subjetivação.

\section{EXPLORANDO AS ETAPAS DA CONSTRU- ÇÃO DA PESQUISA...}

Esta pesquisa foi realizada junto a estudantes do Ensino Superior de uma instituição localizada no interior do Estado de Santa Catarina objetivando explorar as correlações entre o consumismo midiático e os fetichismos do capitalismo contemporâneo. A primeira etapa do nosso trabalho caracterizou-se pela reunião de 10 jovens em uma sala de aula que foram convidados a assistir o vídeo A História das Coisas. ${ }^{1}$ Este vídeo possui a duração de 40 minutos, ele foi editado em duas partes de vinte minutos para favorecer o desenvolvimento de sua reflexão crítica. Após sua exposição foi realizada entrevista com a partir de seis categorias que são apresentadas abaixo.

C1 - Da opinião sobre a propaganda dirigida aos jovens.

As respostas que mais se destacaram foram as dos entrevistados 1 e 3 .

O vídeo retrata muito bem a realidade, quer dizer, se você não consumir tal produto, tal marca de roupa, de tênis, você é posto a parte ou você não faz parte do grupo. Então, na verdade, nós somos o-

\footnotetext{
${ }^{1}$ Disponível em: <https://www.youtube.com/watch?v=7 qFiGMSnNjw>. 
brigados a sermos consumistas, a fazer parte do grupo. Eu tenho que estar na moda para estar inserido naquele grupo. (Entrevistado 1)

Porque senão a gente se sente rejeitado né? nós seres humanos, precisamos estar em grupo, porque a gente não consegue viver sozinho. Então a gente não vive numa ilha, precisamos sempre se agrupar com pessoas que pensam como nós, ou com aqueles que temos mais afinidades, senão não somos aceitos na sociedade. (Entrevistado 3)

A partir destas falas percebe-se que os dois entrevistados possuem forte senso de coletividade. Embora deva-se ressaltar o papel das propagandas no que se refere a produção de tal senso. Nesse caso, pertencer a um grupo social somente torna-se possível no instante em que o jovem adquire um produto para ser pertencente a determinado grupo ou contexto social.

Neste sentido, não existe como não fazer referência a essas falas sem relacioná-las a um artigo escrito por Walter Benjamin (2002) intitulado A Vida dos Estudantes. Nele, o intelectual alemão realiza uma leitura crítica sobre a juventude de seu país no início do século XX, concebendo-a como um produto de uma concepção histórica que confia na infinitude do tempo distinguindo apenas o ritmo dos sujeitos e das épocas que avançam pelas mãos do progresso.

Essa concepção atemporal de história acaba por produzir uma ausência de nexo, uma falta de precisão e de rigor no que se refere à compreensão por parte do sujeito de seu tempo presente. Esse modelo pode ser compreendido como uma pobreza de experiência que hoje associa a juventude a uma coletividade frágil, do ponto de vista existencial já que aproxima os sujeitos em grupos sociais apenas pela aquisição de bens materiais.

C2 - Do conhecimento acerca da obsolescência programada

Destas se destacam as respostas dos entrevistados 2, 4, 5 e 8 .

Eles já fazem os produtos para durar um certo tempo, porque depois de um tempo a gente tem que comprar outro. Antigamente as coisas duravam mais, antigamente você comprava uma geladeira, um fogão, uma tv, os celulares, aqueles tijoIão de antigamente, que você poderia derrubar no chão e na água que eles continuavam funcionando. $E$ hoje não, alguns produtos tem duração de 6 meses. (Entrevistado 2).

Isso seria para manter a economia, então são coisas que a gente não percebe muitas vezes. As nossa tv's já tem um tempo programada de vida. No exemplo do vídeo, ela falou que os computadores são mais finos, e nós realmente queremos coisas mais modernas, com um design novo. Não temos mais opção de escolha, ou tu compra ou tu compra. Não posso escolher ficar com meu computador branquinho $e$ redondo porque depois de um tempo ele não funciona mais. (Entrevistado 4).

Eu acredito que a gente é programado para competir, eu compro meu carro mão para o meu carro me levar a tal lugar, mas porque eu quero um carro melhor do de outra pessoa. A mesma coisa com o computador, o celular, o Notebook e tudo mais. Queremos sempre ter o produto melhor que o outro. Como foi mostrado no vídeo então, que você senta na frente da tv e ela te mostra que tua vida está ruim, que você precisar consumir para satisfazer teu ego e o teu bem estar. E isso, 
pessoalmente, me deixa de cara. Eles passam justamente as propagandas no intervalo das coisas que você gosta de ver. Por exemplo, você assiste a um desenho de manhã, no intervalo de um desenho e outro, só tem brinquedo moderno, um mais legal que o outro. E nos intervalos de novelas só tem aquelas mulheres maravilhosas, com cabelos lindos, com corpo escultural por causa dos shakes para emagrecer. (entrevistado 5).

Eles sabem exatamente como manipular, como te atingir com o horário que eles passam essas propagandas. Como por exemplo, aquela família do Vitor Belfort, aquela família linda, perfeita da tv por assinatura. Então, eles tem a gente na mão. Essa é a impressão que dá. E tem propaganda tão bem arquitetado que fica no subconsciente da gente. Se você fala refrigerante - significa Coca Cola. Se você vai comprar um refrigerante é Coca. Tanto que a Coca Cola pode ficar cem anos sem aparecer no mercado, mas a próxima geração vai saber o que é. (Entrevistado 8).

Essas falas retratam o impacto da obsolescência programada sobre os entrevistados. Todos eles afirmaram em suas respostas saberem o resultado direto da obsolescência programada, contudo admitem a dificuldade em diminuir seu consumo.

Isso porque a obsolescência programada é uma questão de superestrutura e segundo Benjamin (1985), esta se modifica mais lentamente que a base econômica. Estas superestruturas possuem relação direta com o que Matos (2010), chama de espetáculo moderno, isto é, um canto épico que não canta a guerra, os homens e suas armas como na época do teatro grego, mas sobretudo as mercadorias e suas paixões.

Neste sentido, a mercadoria torna-se mais do que um mero item. Ela perpetua-se como um totem pelo qual todo indivíduo deve se sacrificar entregando todo o seu dinheiro com a necessidade de oferecer a si mesmo como sacrifício, produzindo dependência que termina por levá-lo a ruína econômica.

Outra questão extremamente importante refere-se ao papel da manipulação pela promessa estética do valor de uso, da utilidade da mercadoria e da beleza consagrada a serviço da realização do valor de troca, a fim de suscitar o desejo de posse. Neste sentido, segundo Matos (2010), a obsolescência programada é a própria promessa da supressão de uma necessidade sem fim que se efetiva pela relação afetiva do sujeito com o seu objeto.

Por conta deste aspecto, é que pode-se afirmar que o amor pelo mundo resume-se, na nossa época ao amor pela mercadoria e pela possibilidade do sujeito sempre comprar no dia de manhã um novo lançamento da indústria.

C3 - Dos cinco produtos mais utilizados pelos entrevistados

Nesta categoria destacam-se as falas dos entrevistados 1, 6 e 8 .

Roupa" "Computador" "Créditos para ceIular" "Comida" "Produtos de beleza" "Produto de higiene. (Entrevistado 1).

Por exemplo, oxampoo, poderiamos usar o mais simples que nosso cabelo iria ficar limpo igual, mas a gente usa aqueles que as propagandas mostram os cabelos mais sedosos e lisinhos. (Entrevistado 6).

Eu vejo que sai um xampoo novo na propaganda, aqueles para pontas duplas, já fui correndo comprar. Se vai funcionar, eu não sei, mas eu quero comprar. (Entrevis-

https://periodicos.unifap.br/index.php/estacao Macapá, v. 6, n. 2, p. 53-65, maio/ago. 2016 
tado 8).

Essas falas registram a importância dada pelos entrevistados a produtos de consumo em vez da aquisição de gêneros de primeira necessidade. Evidentemente que num primeiro momento poderíamos ressaltar os aspectos que envolvem a faixa etária dos participantes, todos jovens universitários que moram com seus pais e não precisariam desprender uma grande preocupação com esses gêneros de primeira necessidade. No entanto, a partir da produção de um olhar um pouco mais apurado, observa-se que essa o supérfluo está presente até nos chamados produtos da Cesta Básica não havendo espaço para a generalização de uma preocupação dos mais jovens com outra coisa que não seja a estética da posse. Esse sentimento, segundo Witte (2008), acaba por criar um processo contínuo de transformação pelo qual a mídia acaba produzindo uma modificação das condições materiais de produção e de existência.

Possuir um produto da última geração significa estar de acordo com alguma tendência que reflete no espelho do mundo contemporâneo a aparência em que a mercadoria ganha vida própria.

C4 - Do conseguir ou não viver sem Internet

Nesta categoria destacam-se as respostas dos entrevistados 2, 3, 6, 7, 8 .

Acho que se a pessoa nunca teve internet ela vive sem sim. Mas ela depende de banco para receber, depende da delegacia para registrar, depende de uma série de coisas, de comércio. (Entrevistado 2). No meu trabalho, a internet é via rádio. Então no momento que dá uma chuva, tudo para de funcionar, fica todo mundo de braço cruzado se olhando. (Entrevistado 3).

A partir do momento que você tem o contato com a internet, você não consegue viver sem. (Entrevistado 6).

Até os meus quatorze anos eu fiquei sem internet. (Entrevistado 7).

Consegue sim, mas vive mal. (Entrevistado 8).

Analisando estas falas ressalta-se que os entrevistados possuem uma concepção atualizada sobre a importância da Internet nas suas vidas a ponto de afirmarem que suas elas seriam muito difíceis de sem a presença dessa ferramenta.

Um apontamento que pode sugerir a equivalência do virtual sobre o real no mundo de hoje, pois segundo Matos (2010), o vínculo de dependência dos sujeitos em relação a Internet atesta o fim do culto a origem. Tudo se torna repetição da repetição e à originalidade torna-se um esforço inútil, pois a Internet multiplica ao infinito as coisas pelas mãos do artifício da produtividade.

C5 - De como a juventude é retratada nas propagandas

Neste item destacam-se as respostas dos entrevistados 2, 4 e 5.

Retratam o jovem como se a gente não tivesse mais o que fazer da vida, ficar falando o dia todo no telefone. Tem uma propaganda que mostra os namorados um do lado do outro mandando mensagem de amor. E é bem interessante isso porque aconteceu comigo uma vez, eu tinha um namorado e pra gente não brigar na frente de todo mundo, a gente brigava 
por mensagem. Eu e ele sentados no sofá e pra não mostrar pra todo mundo que a gente tava brigando, a gente brigava por mensagem. (Entrevistado 2).

Vamos começar pela da Tim, aquele idiota fica no telefone ligando para Grazi Massafera, então vamos pensar na propaganda, quantas pessoas ele teve que ligar para conseguir o número dela. E é isso que eles querem passar pra nós, vamos fazer várias ligações. Um jovem que poderia ser bem melhor retratado, e o pior é que está representando todos nós. (Entrevistado 4).

As relações sociais estão decaindo. Uma vez fui na pizzaria e na mesa do lado tinha um casal, e o tempo todo eles ficaram mexendo no celular, cada um no seu. E não era mensagem, era o facebook, ficavam olhando as novidades. Aproxima quem tá longe e afasta quem tá perto. Quanto maiores os amigos virtuais, menores os amigos reais (Entrevistado 5).

Todas estas respostas apontam o descontentamento dos entrevistados em relação ao modo como a juventude é representada nas propagandas seja através de estereótipos, seja por meio de imagens que não correspondem as suas práticas sociais. 0 afastamento das relações materiais também é evidenciado pelos entrevistados como um entrave nos dias de hoje, aumentando a predominância do virtual como efeito imediato de práticas sociais cada vez mais fluidas. A consequência deste processo pode ser representada pela perda da experiência coletiva na contemporaneidade.

Em Experiência e Pobreza, Walter Benjamin (1985) proclamava que a sociedade moderna entrara num ritmo acelerado de vida que contribuiria cada vez mais para a automatização do cotidiano. As mudanças sociais ocorridas na Modernidade, sobretudo com o aparecimento da tecnologia e as mudanças ocorridas no mundo do trabalho, implicaram numa transformação radical nas relações entre as pessoas com a materialidade e com o tempo.

Há que se salientar os impactos destas transformações ocorreram não de forma linear, mas sim a partir da transversalidade das práticas culturais envoltas dentro dos contextos das formas de governamentalidade.

Talvez uma das consequências mais importantes destas transformações seja a perda da experiência. Quase como máquinas os sujeitos modernos seguem absorvidos pelos afazeres cotidianos anestesiados como se fossem partes da engrenagem de alguma máquina, nesse sentido o sujeito moderno corre, corre e, ao final do dia, não consegue saber o que fez. Benjamin (1985) fala de como este sujeito encontra-se diante de uma ausência de experiência sendo sugado pelo excesso de informações que o mundo moderno oportuniza. Nos dias de hoje o sujeito não tem tempo a perder principalmente com pequenas coisas... Há que se pensar grande:

Pobreza de experiência: não se deve imaginar que os homens aspirem a novas experiências. Não eles aspiram libertar-se de toda experiência, aspiram a um mundo em que possam ostentar tão pura e claramente sua pobreza externa e interna, que algo de descente possa resultar disso. Nem sempre eles são ignorantes ou inexperientes. Muitas vezes podemos afirmar o oposto: eles "devoram" tudo, a "cultura" e os "homens", e ficam saciados e exaustos. "Vocês estão todos cansados e tudo porque não concentram todos os 
seus pensamentos num plano totalmente simples mas absolutamente grandioso." Ao cansaço segue-se o sono, e não é raro que o sonho compense a tristeza e o desanimo do dia realizando a existência inteiramente simples e absolutamente grandiosa que não pode ser realizada durante o dia por falta de forças. (BENJAMIN, 1985, p. 118)

A falta de tempo e a pobreza da experiência poderíamos dizer são males que atingem em cheio a subjetividade dos jovens nos dias de hoje e por conta disto, fica tão difícil visualizar qualquer alternativa para o rompimento deste processo além da queixa e da insatisfação como registrado nas falas dos entrevistados.

C6 - Do conhecimento acerca do consumo sustentável

Em relação ao item seis: consumo eficiente: Destacam-se as respostas de nove entrevistados sendo estes: 01, 02, 03, 05, 06, 07, 08, 09 e 10 conforme apontamos abaixo:

Eu acho que essa questão da internet e da tecnologia ela vai deixando a gente muito individualista. Tudo é eu e meu computador, meu celular, minha tv que passa os filmes que eu gosto, os programas que eu gosto. (Entrevistado 01).

Eu quase não assisto televisão, mas quem que não gosta de ver os vídeos no youtube, e enfiaram propagandas, e você não consegue não ver, porque durante 5 segundos você é obrigado a ver aquilo que eles quem. Já aconteceu comigo de tentar ver o vídeo mas a propaganda ta tão interessante que eu fico assistindo até o final. (Entrevistado 02).

Seria consumir aquilo que você realmente precisa, adquirir produtos que venham de uma maneira idônea. (Entrevistado 03). Tem vários produtos que usam escravos infantis. Uma vez ouvi falar que a Nike tem trabalho escravo para colar os tênis. Perfumes de uma marca bem famosa também eram crianças que colhiam as flores para produção da essência. (Entrevistado 05).

E nós não vamos atras dessas coisas para saber, porque na verdade a gente não quer saber mesmo, porque vai atingir a gente. (Entrevistado 06).

Outra questão é que você chega em bairros carentes, de dez casas, oito terão antena da sky. Muitas vezes deixam de comprar coisas que são prioridades, pra assinar a tv a cabo. (Entrevistado 07).

Não dá de julgar, porque tudo isso é muito influenciável. Mas se pensar em tudo isso, tudo isso é muito idiota, porque, você trabalha o dia todo para pagar uma televisão que você não tem tempo de assistir. Você chega cansado em casa, você senta pra ver um filme e acaba dormindo. Pra no outro dia de manhã, você começar tudo de novo. (Entrevistado 08).

Mas ele resolveram o problema fazendo uma tv que você coloca o cabo usb e consegue navega na internet na própria tv. (Entrevistado 09).

Mas eles tão vendo que a televisão tá ficando meio de lado, porque é muita internet eles conseguiram colocar propaganda." (Entrevistado 10).

Essas falas registram que os entrevistados possuem uma compreensão adequada sobre a importância do consumo de produtos eficientes comprometidos com as demandas dessa nova sociedade que surge a partir do início do século XXI.

Entretanto, essas falas também registram a necessidade que os entrevistados 
possuem em relatar os motivos pelos quais essa sociedade de rede, como sugere Benjamin (1985), é incapaz de dissociar a palavra consciência dos aparatos tecnológicos. Como se a tecnologia fosse a única responsável por conduzir o processo de uma sociedade mais justa, igualitária e sem discriminações.

C7 - Da opinião acerca das propagandas de cervejas e bancos

Em relação ao último item: propagandas de cervejas e dos bancos. Destacam-se as respostas dos entrevistados 01, 02,03 e 06 descritas abaixo:

Propaganda enganosa, fui no mercado $e$ comprei e não adiantou em nada. Mas a gente sempre cai e também acho que não fui o único. (Entrevistado 01).

Mas dos bancos, eles querem fazer a gente confiar neles de olho fechado. Principalmente os empréstimos, pra montar a casa dos teus sonhos. Só que o problema que não temos paciência pra olhar as taxas do banco, é taxa de tudo e a gente não confere. Porque às vezes a taxa é de 30 centavos, então não damos bola pra isso, você não vai reclamar, mas o banco tem milhões de clientes e é ai que está o lucro. (Entrevistado 02).

Tem uma propaganda que é muita sugestiva, que fica um pouco fora, do que ta na pergunta, que é a do Axe, que é nada haver aquilo. Muito machista." (Entrevistado 03).

As de cerveja já tão mudando, antes mostravam os homens bebendo, as gurias de biquíni e agora são as mulheres tomando uma cerveja e o cara bonito passando. Ou seja, eles mudaram a forma de atingir, estão atingindo as mulheres. (Entrevistado 06).
As respostas destes entrevistados apontam para o fato de que houve uma mudança perceptual nas relações dos jovens com estes estilos de propagandas sinalizando uma maior preocupação com a autoimagem principalmente das mulheres e da felicidade.

Estes temas por sua vez precisam ser problematizados com um cuidado maior à medida que estas atenuações presentes em comerciais destas instituições não significam uma maior sensibilização do papel da mulher na sociedade, mas apenas um refinamento de questões que envolvem a sutileza das demandas dessa nova sociedade de consumo que prioriza os aspectos estéticos voltados para uma conscientização que não é emancipadora, mas apenas reforçadora da submissão, sobretudo dos mais jovens. Essa premissa revela que o sistema capitalista vai além de qualquer desdobramento econômico inscrevendo-se numa perspectiva ética e estética, ou nas palavras de Benjamin (2013, p. 23):

O capitalismo é uma religião puramente de culto, desprovida de dogma. No Ocidente, o capitalismo se desenvolveu como parasita do cristianismo - o que precisa ser demonstrado não só com base no calvinismo, mas também com base em todas as tendências cristãs ortodoxas -, de tal forma que, no final das contas, sua história é essencialmente a história de seu parasita, ou seja, do capitalismo. Comparação entre as imagens dos santos de diversas religiões, de um lado, e das células bancárias de diversos Estados, de outro.

\section{FETICHISMOS DA CARNE NO NOSSO CA- PITALISMO CONTEMPORÂNEO}


A noção de fetichismo em Walter Benjamin é, na realidade, uma apropriação do mesmo conceito presente nos trabalhos de Marx e de Freud. Contudo, há que se ressaltar se para Marx, por um lado, o fetichismo converte-se em efeito desdobrado da vida útil da mercadoria e, em Freud, por outro lado, o fetichismo ganha os contornos de uma prática de perversão, Benjamin, por sua vez, irá considerar o fetichismo como o que Matos (2010) designa de sex apeal do inorgânico. Ou seja, um acontecimento específico da Modernidade em que as barreiras do orgânico sofrem uma queda e o mundo inanimado mistura-se com a vida real. Nesse sentido, o que Benjamin (1975) irá propor é que o fetichismo é um fenômeno onírico.

Essa constatação implica na possibilidade de se compreender o fetichismo como uma espécie de alegoria da condição de miserabilidade existencial vivenciada pelo sujeito no contexto da nossa contemporaneidade. Nós, sujeitos provenientes da modernidade convencionamo-nos a acreditar que a ciência, a tecnologia e o capital colocaram a humanidade sob a marcha do progresso. Entretanto, Benjamin (1991) irá problematizar essa visão teleológica de história e de temporalidade da qual nos tornamos reféns. Deste modo, o sujeito da contempozê-lo, fica destituído de pensar qualquer proposta de vida diferentemente daquela orquestrada pela governamentalidade capitalista.

Como compreender este acontecimento? Como superar a condição de miserabilidade no mundo de hoje? Um mundo desprovido de grandes revoluções ou grandes projetos utópicos? Cabe a cada pessoa perceber a imagem possível de uma experiência transraneidade torna-se animal isolado e, ao fa-

formadora. Experiência que só pode emergir pelas mãos da memória involuntária. Um gesto, um olhar, a prova de um sabor, um cheiro, são sensações que podem provocar o arrebatamento de um tempo reencontrado (BENJAMIN, 1975).

Neste sentido, é preciso operar um método dialético baseado na montagem de múltiplos aspectos. O surrealismo, a poesia baudeleriana e o romance de Proust $^{\underline{2}}$ são pensados como alegorias possíveis da modernidade. Abalos contraditórios que emitem um sinal contra o capitalismo. Um sinal que é estético, mas que não deixa de ser combativo como qualquer outro aspecto revolucionário. Um exemplo desta leitura é constatado na leitura feita por Benjamin em relação à Revolução de 1830.

Em vez de construir ensaios sobre os processos revolucionários decorrentes dos conflitos entre as classes, Benjamin situa como nesta revolução, houve uma luta contra o tempo do capitalismo, tanto que um dos primeiros alvos dos revoltosos foram as torres dos relógios. Não devemos enxergar neste acontecimento um processo nostálgico de perda, mas sim um movimento de luta contra o capital, pois na opinião de Benjamin (1975), a verdadeira revolução não será deflagrada pela luta do operariado em tomar os modos de produção da sociedade capitalista, mas sim por uma nova reflexão do sujeito contra o seu tempo.

O capital projeta o futuro, e Benjamin situa no passado os elementos que permitem ao sujeito recusar esteticamente todos os encantos do capitalismo e esta é a denúncia empreendida por Benjamin. A felicidade é

\footnotetext{
${ }^{2}$ Tanto Baudelaire quanto Proust são escritores que, na opinião de Benjamin, tentam atualizar o conceito de experiência coletiva que é sufocado pelas mãos do capitalismo.
} 
algo que é sempre tocada por um sentimento de falta, neste sentido, as galerias de Paris no Século XIX e os nossos Shoppings Centers no Século XXI, podem tranquilamente ser associados como moradas do sonho.

Este estudo caracteriza-se como uma análise sobre o consumismo midiático no contexto do capitalismo contemporâneo a partir dos estudos sobre fetichismos inaugurados por Walter Benjamin. A concepção benjaminiana de capitalismo moderno refere-se à compreensão de que esse momento histórico é fortemente marcado pelas correlações entre os conceitos de fetichismo e estado de exceção.

Cada uma desses conceitos corresponde a possível articulação entre a modernidade e a história tomada como campo de possibilidades e de intensas transformações vivenciadas pelos sujeitos, principalmente em relação à cultura e ao tempo. Particularmente, o fetichismo é um fenômeno da modernidade que desperta o encantamento, no entanto Benjamin considera que tal encantamento é na verdade um acontecimento onírico. Ou seja, ele existe para subsidiar sonhos e conquistas em meio a miséria do mundo contemporâneo.

A conclusão paradoxal que se abre a partir dessa constatação é que passa a existir no interior do processo do fetichismo, um sujeito constituído pelo que Benjamin chama de dialética da imobilidade, e o tempo contemporâneo estrutura-se por meio desta imobilidade. A repetição é a marca precisa desse momento histórico em que dias de luta e paz convivem lado a lado com a assustadora miserabilidade da rotina presente nas vidas de produção e de consumo. Por outro lado, a leitura produzida por Benjamin contextualiza o capitalismo não mais pelo viés dos modos de produção, mas também pelos modos de consumo, pois é justamente o consumo que está em jogo nos desdobramentos da prática capitalista.

Fruto de um desejo onírico de vislumbrar nos sujeitos todas as potencialidades de uma vida plena, mas completamente anestesiada o fetichismo escurece a vista não fazendo com o sujeito visualize qualquer possibilidade de recusa perante a miserabilidade da vida capitalista. Um corte precisa ser produzido, e este corte só pode ser efetivado por meio de uma característica presente pela melancolia ativa, cujo ápice é o pensamento de Benjamin (1975).

Saturno é o astro do luto impossível. 0 planeta assemelha-se a um símbolo da melancolia cuja referência maior é Baudelaire (2003). O poeta que se desencanta pela onírica da modernidade percorrendo a multidão para perder-se, não conseguindo fixar um olhar de reconhecimento, mas sim de estranhamento. Essa imagem refere-se à representação do poeta como Anjo atingido pelo progresso e tal como o poeta nossa vida é constituída sob o emblema de um anjo que a qualquer momento pode vir a transformar-se num demônio, sobretudo, quando estamos sob o efeito de uma paixão (BENJAMIN, 1975).

$E$, que paixão é mais intensa para o sujeito nos dias de hoje do que a mídia? A mídia produz uma fantasmagoria do tempo. Eis uma ilustração possível deste processo: o espectro de um jogador que nos percebe. $E$, contemporaneamente, somos como este espectro.

Benjamin (1975, p. 10), explicita que "Cansados e entregues aos vícios, apostamos tudo numa só jogada, porém sempre temos a possibilidade de recomeçar do zero", pois para o autor: 
Somos todos jogadores contaminados pela onírica da propaganda. Ela é sedutora porque produz uma imagem que flui como um processo tal qual uma rua de mão única. Essa é a alegoria que deve ser pensada para formularmos uma crítica às teses progressistas de que a sociedade caminha num único sentido, de que somente os vencedores podem e devem reivindicar um lugar dentro deste contexto do capitalismo contemporâneo.

Sendo assim, a questão mais importante seria pensarmos pelas mãos da dialética da imobilidade ${ }^{3}$ pela mídia como formadora de um estado de exceção, pois o Estado moderno não é tão laico ${ }^{4}$ como parece. Benjamin $(1975$, p. 30$)$, sugere que "na figura do príncipe centralizam-se ações que discorre sobre a vida e a morte dos sujeitos tal qual no terreno da religiosidade".

O Estado é produto de uma criação continua aberta e teológica e a modernidade é o tempo do Estado de exceção. Não existe democracia, mas apenas medo e insegurança. Pelas mãos da razão instrumental é a excelência da barbárie transformando a vida cotidiana num exercício de massacre que é mascarado pela propaganda. Neste sentido, não há como falar sobre este artefato sem recorrer a noção de fetiche pelas mãos deste acontecimento (BENJAMIN, 1975).

Seguindo essa linha de raciocínio, analisando a questão da propaganda no mundo capitalista, as transformações sociais e culturais pelas quais a sociedade ocidental passa no mundo contemporâneo podem ser associadas ao que Benjamin (1985, p.35)

\footnotetext{
${ }^{3}$ Dialética é a junção da tese, antítese e síntese.

${ }^{4}$ Laico é o estado sem religião.

chama de "teologia do inferno". Acompanhado Baudelaire para quem a modernidade é a queda de Deus. Contudo, não se trata de compreender uma cisão entre dois mundos, mas sim a denuncia sobre a falsidade dos valores sobre os quais a vida capitalista se funda (BENJAMIN, 1985).

Operando por antíteses, Baudelaire $(2003$, p. 01) propõe a lei dos contrastes onde governa a ordem moral e a ordem física. Por isso há no homem, duas postulações simultâneas, uma em direção a Deus, outra a Satã como confirma o célebre poema Ao Leitor em que se lê:

\section{Ao Leitor}

A tolice, o pecado, o logro, a mesquinhez Habitam nosso corpo e o espírito vicia, $\mathrm{E}$ adoráveis remorsos sempre nos saciam. Como o mendigo exibe a sua sordidez. Fiéis ao pecado, a contrição nos amordaça; Impomos alto preço à infâmia confessada, E alegre retornamos à lodosa estrada, $\mathrm{Na}$ ilusão de que o pranto as nódoas nos desfaça. Na almofada do mal é Satã Trismegisto Quem docemente nosso espírito consola, E o metal puro da vontade estão se evoca Por obra deste sábio que age sem ser visto. É o diabo que nos move e até nos manuseia! Em tudo que repugna, uma joia encontramos; Dia após dia, para o Inferno caminhamos, Sem medo algum, dentro da treva que nauseia. Assim como um voraz devasso beija e suga $O$ seio murcho que lhe oferta uma vadia, Furtamos ao acaso uma carícia esguia Para espremê-la qual laranja que se enruga. Espesso, a fervilhar, qual um milhão de helmintos, Em nosso crânio um povo de demônios cresce, E, ao respirarmos, aos pulmões a morte desce, Rio invisível, com lamentos indistintos.

Se o veneno, a paixão, o estupro, a punhalada Não bordaram ainda com dese- 
nhos finos A trama vã de nossos míseros destinos, É que nossa alma arriscou pouco ou quase nada. Em meio às hienas, às serpentes, aos chacais, Aos símios, escorpiões, abutres e panteras, Aos monstros ululantes e às viscosas feras, No lodaçal de nossos vícios ancestrais. Um há mais feio, mais iníquo, mais imundo! Sem grandes gestos ou sequer lançar um grito, Da Terra, por prazer, faria um só detrito $E$ num bocejo imenso engoliria o mundo; É o Tédio! - O olhar esquivo à mínima emoção, Com patíbulos sonha, ao cachimbo agarrado. Tu o conheces, leitor, ao monstro delicado - Hipócrita leitor, meu igual, meu irmão.

Da mesma maneira que o poeta, o leitor seria o experimentador dos sentimentos contraditórios em que o horror e a exaltação pela vida entrelaçam-se, fazendo com o capitalismo seja analisado como um torpor mítico que se abateu sobre o século, cuja metáfora seria a de um constante sonho em estado de vigília (BENJAMIN, 1985).

Para se entender esse processo de forma mais precisa deve-se recorrer à leitura empreendida por Benjamin (1984, p. 120) em relação ao Drama Barroco Alemão. Para ele, "o período compreendido entre os século XVII e XIX é a época de exacerbação dessa teologia do inferno. Alegoria, publicidade, e a tipologia dos tipos mais desprezíveis: o tirano, a prostituta e o especulador".

O capitalismo seria, portanto, o mundo dos duplos invertidos em que o tirano torna-se um mártir, o mártir um tirano e a prostituta uma especuladora. Eis o universo dos paradoxos capitalista: à modernidade falta um princípio de razão suficiente, pois o capitalismo por meio da propaganda evoca crueldades cometidas e tormentos sofridos, no contexto das terríveis circunstâncias de vida que reinam na sociedade contemporânea.

E, o paradoxo que se abre nesse contexto é: a sociedade seria o inferno dos anjos e o paraíso dos demônios. As condições de trabalho as quais são submetidas os trabalhadores fazem de Dante uma presença infalível, a metáfora do inferno, ampliando o lugar circunscrito à existência dos sujeitos nos dias de hoje (BENJAMIN, 1984).

\section{CONSIDERAÇÕES FINAIS}

Qual o maior êxito do sistema capitalista? Certamente a resposta para esse questionamento não se encontra somente na economia, mas também na estética e na história. Paul Singer (2002) sugere que o capitalismo não é, em absoluto, um sistema natural, mas sim uma produção histórica construída do homem, para o homem e que hoje apresenta-se como a ideologia dominante priorizando princípios como a competição, o individualismo e o acúmulo de bens. Contudo, estes estímulos mostram-se contrários aos valores empregados pela sociedade nos dias de hoje.

Cada vez mais assistimos a um espetáculo midiático em que grandes corporações exigem um mundo "mais sensível" e um sujeito fortemente engajado nas propostas de conscientização e participação social. Isso levaria um sujeito ingênuo a crer que o capitalismo na contemporaneidade tenha se tornado um sistema político e social "humano, demasiadamente humano".

Contudo, essa fachada é demolida ao recorrermos ao pensamento eminentemente cruel de Walter Benjamin para sinalizarmos que o capitalismo trinfou na nossa sociedade porque ele produz um desejo onírico no sujeito. O capitalismo é segundo Benjamin 
(1985) a morada do sonho. E a constatação mais explosiva deste processo é que tratase de um sonho lúcido que é reificada pelas mãos do fetichismo.

Benjamin (1985) apresenta o fetichismo como o desejo que o sujeito possui em relação a algo. Um desejo que nunca é preenchido na sua totalidade. Imerso nessa cortina de fumaça que são as relações sociais nos dias de hoje o sujeito não consegue visualizar qualquer proposta de ruptura em relação a este processo porque o fetichismo é altamente sedutor.

Certamente que se trata de uma sedução melancólica, pois o sujeito jamais consegue dar um passo além. Ou seja, inscreve no seu corpo, na sua subjetividade elementos responsáveis por tornar o capitalismo mais do que um sistema de mercadoria, mas um estilo de vida, algo que não pode abrir mão, algo que não consegue desvencilhar.

Neste sentido, a pesquisa que ora apresentamos mostra efetivamente como todos os entrevistados não conseguiram emitir uma resposta abrangente sobre sua condição de consumidores no mundo de hoje. Seja porque introjetaram nas suas subjetividades elementos de um capitalismo voraz, seja porque adotaram um estilo capitalista de ser marcado, sobretudo pelos valores ecológicos e de conscientização.

\section{REFERÊNCIAS}

BAUDELAIRE, C. As flores do mal: texto integral. São Paulo: Martin Claret, 2003. BENJAMIN, W. A modernidade e os modernos. Rio de Janeiro (RJ): Tempo Brasileiro, 1975.

. Origem do drama barroco alemão. São Paulo (SP): Brasiliense, 1984.

. Magia e técnica arte e política: ensaios sobre literatura e historia da cultura. São Paulo (SP): Brasiliense, 1985.

. Charles Baudelaire: um lírico no auge do capitalismo. 2. ed. São Paulo (SP): Brasiliense, 1991.

A vida dos estudantes. In: BENJAMIN, W. Reflexões sobre a criança, o brinquedo e a educação. São Paulo: 2002.

. O capitalismo como religião. Belo Horizonte: Boitempo, 2013.

MATOS, O. Benjaminianas: cultura capitalista e fetichismo contemporâneo. São Paulo: UNESP, 2010.

SINGER, P. Introdução à economia solidária. São Paulo: Fundação Perseu Abramo,2002.

WITTE, B. A escrita na era de sua reprodutibilidade técnica. In: COUTO, E. S.; DAMIÃO, C. M. Walter Benjamin: formas de percepção estética na modernidade. Salvador: Instituto Goethe, 2008.

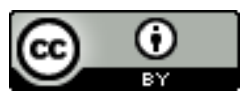

License information: This is an openaccess article distributed under the terms of the Creative Commons Attribution License, which permits unrestricted use, distribution, and reproduction in any medium, provided the original work is properly cited.

Artigo recebido em 11 de setembro de 2015.

Avaliado em 20 de setembro de 2016.

Aceito em 04 de outubro de 2016.

Publicado em 03 de novembro de 2016.

\section{Como citar este artigo (ABNT):}

SOLER, Rodrigo Diaz de Vivar y. Fetichismos da carne: consumismo midiático no capitalismo contemporâneo. Estação Científica (UNIFAP), Macapá, v. 6, n. 2, p. 53-65, maio/ago. 2016. 